\title{
INFLUENCE OF SPECIFICATIONS ACCORDING TO THE SYSTEM OF GEOMETRICAL PRODUCT SPECIFICATIONS (GPS) ON SCRAP IN TECHNICAL PRODUCTS
}

\author{
Gust, Peter; \\ Sersch, Alina; \\ Kuhlmeier, Marco \\ University of Wuppertal
}

\begin{abstract}
The success of a company is directly linked to its economic objectives. One of the elementary objectives is to maximize profit by reducing the company's own costs in order to increase competitiveness in the market. State of the art is the function-oriented and unambiguous technical specification through the application of Geometrical Product Specifications (GPS). Linking costs related to the GPS system is currently only possible to a limited extent. This contribution presents an approach to quantify costs based on statistical tolerance analysis. The application is intended to determine the impact of a GPS-compliant specification in direct comparison to a non-compliant technical drawing by analyzing scrap rates. In this way, an assessment of the changes associated with the consistent application of the GPS system should be achieved. The results of the study show that a comparison is only possible to a certain degree due to the different characteristics. Based on this finding, an extended evaluation methodology is described.
\end{abstract}

Keywords: Cost linkage, Design for X (DfX), Design practice, Geometrical Product Specifications (GPS), Tolerance representation and management

\author{
Contact: \\ Sersch, Alina \\ University of Wuppertal \\ School of Mechanical Engineering and Safety Engineering \\ Germany \\ alina.sersch@uni-wuppertal.de
}

Cite this article: Gust, P., Sersch, A., Kuhlmeier, M. (2021) 'Influence of Specifications According to the System of Geometrical Product Specifications (GPS) on Scrap in Technical Products', in Proceedings of the International Conference on Engineering Design (ICED21), Gothenburg, Sweden, 16-20 August 2021. DOI:10.1017/pds.2021.446 


\section{INTRODUCTION}

The present age is characterized by advancing technological development, digitization and globalization. The worldwide interdependencies brought about by globalization impact different areas of human activity, which can be seen in Figure 1. In addition to the political, social and ecological dimensions, it also affects economic processes (Vornholz, 2015). Globalization offers opportunities, but at the same time poses risks for states, companies and the individual. This article will focus on the challenges of economic globalization, especially as they affect companies and enterprises.

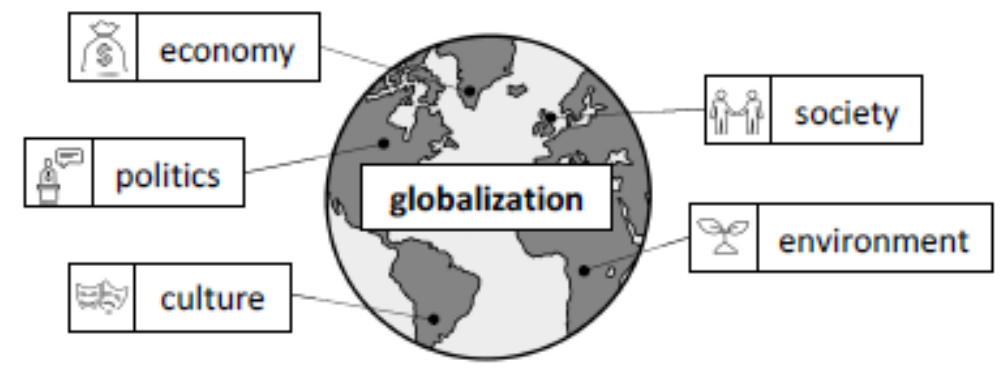

Figure 1. Dimensions of globalization based on (Vornholz, 2015)

Internationally operating companies have to adapt to constantly changing work environments and competitive situations. Furthermore, with changes in logistics and supply structures, and increasing customer demands, the requirements for international cooperation in corporate production and development departments are gaining in scope and importance.

In the ongoing pursuit of economic growth, cost reductions are a prime means for maintaining competitiveness. In order to reduce costs, technological communications, for example, should be in a uniform language, namely via the Geometrical Product Specifications (GPS) system (ISO/TC 213, 2008). The importance of standardized technological communications is not limited to globally operating enterprises, although it is particularly apparent in these cases. On a more local scope, standardization of communications can, nevertheless, offer advantages for enterprises. In addition, successful local implementation of GPS is a prerequisite for broader corporate alignment. Although GPS has been increasingly anchored in standardization work since 1996, it is still not in universal use. This is due to several factors. However, the non- (or only partial) use of the GPS system can lead to a growth of scrap in production, which - like any other form of deviation - has an influence on quality. The assurance that predefined quality requirements will be maintained, is based on limiting these deviations. A basic assumption of the GPS system is that specification limits correspond - as tolerance limits - to the functional limits of the component (ISO 8015:2011). In the development process, geometrical tolerancing can be divided into specification, allocation and optimization tasks, which are performed by the designer (Armilotta, 2011). The purpose of tolerance specification is to define the relevant types of tolerance, while allocation aims at a quantitative definition of tolerance values. As a further field of activity, tolerance analysis deals in particular with the effects of geometric deviations on the individual components or assemblies and the functional properties ascribed to them.

By using various tools, the designer can be supported in these tasks, whose complexity and responsibility should not be underestimated. One possible form of support is computer-aided geometric dimensioning and tolerancing (Sigmetrix, 2020). Furthermore, tolerance analysis software is often used manually - either with a statistical or worst-case approach - for tolerance allocation in trial and error (Haq, 2005).

By using the GPS system, various specifications in technical products can be described. The early use of these tools is a good way to control product quality from the beginning of the development process. A particular challenge in this context is the objective determination of costs directly related to product quality. These costs are of great importance for companies, as they represent a non-negligible impact.

The following research questions will now be addressed:

- What typical application deficiencies can be found in technical drawings, taking into account current GPS standards?

- Can scrap levels be realistically and reproducibly determined by statistical tolerance analysis?

- Can scrap (as determined) be directly and comprehensively linked to GPS system costs? 


\section{STATE OF THE ART}

In the following sections, the standards system of Geometrical Product Specifications and its role as a means of communication will be explained in greater detail and the current situation of the application - with its challenges - will be described. Section 2 will conclude with an introduction to incorrect, ambiguous, and/or incomplete specification examples. Cases of specifications regularly found in technical drawings will be listed, and problems arising from these specifications will be described from a general point of view.

\subsection{Geometrical Product Specifications}

The system of Geometrical Product Specifications is used in technical documentation for the description of the geometrical characteristics of components (ISO 14638:2015). On the basis of this symbolic language, geometrical structures can be described nonverbally in a function-oriented way, and principles and measuring equipment can be relied upon for verification. Hence the language of symbols can affect various areas of an enterprise, such as design, manufacturing, and/or verification.

ISO standards for "Dimensional and geometrical product specifications and verification" are created and updated by the international committee ISO/TC213, founded in 1996 (ISO/TC 213, 2008). As well as dimensional and geometrical tolerances, these include surface properties (International Organization for Standardization (ISO), 2020). The field of metrology, for example, includes standards for verification, measuring equipment and calibration. ISO publications introduce the basic principles and rules of the standards system and provide a comprehensive range of symbols. Among other things, symbols for application in the symbol section of the tolerance indicator and in the section for zone, geometry element and feature can be named. Figure 2 shows an overview of the symbols for geometrical tolerances in the GPS system.

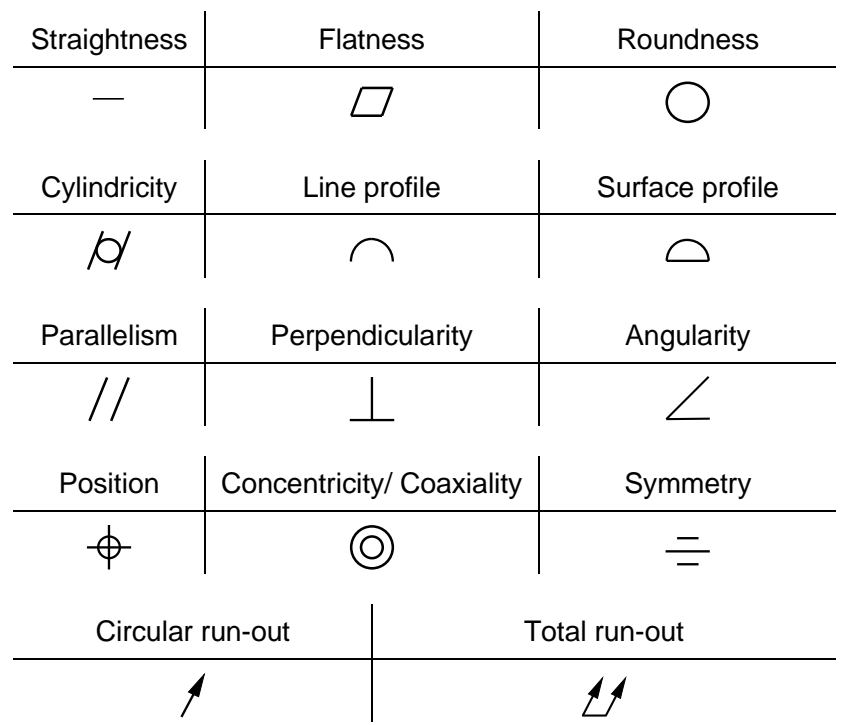

Figure 2. Overview of symbols for geometrical tolerances (according to ISO 1101:2017)

In accordance with the functional control and duality principles, the designer is responsible for any ambiguities that may arise from the approximation of the functional operator by the specification operator (ISO 8015:2011). However, the designer, like any other user of GPS standards, faces challenges (Sersch and Gust, 2018). At the same time, with the digitization of manufacturing and the idea of model-based definition (MBD), there is a growing interest in effective specification and verification (Macleod, 2020). Enterprises are confronted with their current way of specification and recognize the need to look at specification standards in more detail. Acceptance of new norms presents a challenge, because established habits have to be broken, but the GPS system can be understood as an extension of existing practices. Tensions between challenges and ambitions to follow the state of the art are discussed below.

Due to the high level of detail, the standards system consists of a large number of individually published standards distributed over numerous documents (International Organization for 
Standardization (ISO), March 2020: 150 standards under TC 213). The perceived level of complexity, combined with the dynamics of the standards, makes it difficult to build up know-how and skills. Consequently, acceptance of the system suffers, as core advantages are no longer recognized and - for the overwhelmed user - disadvantages seem to dominate.

Moreover, complexity can lead not only to problems of acceptance, but even to the exclusive use of selected standards, or only parts of them. In the past, doubts about fragmentation in the application of standards - a factor which threatens the implementation of the standards system throughout an enterprise - have been expressed in the committee TC 213 (Morse et al., 2018).

Integration of GPS must be understood holistically as affecting the entire product life cycle and involving employees from many different areas, such as development, production, metrology, and technical procurement. This, of course, requires considerable human and financial resources, a fact, which should not be underestimated. Due to the long-term nature of the implementation, enterprises often hesitate to introduce the system, because the benefits will only become apparent in the medium or long term. An approach based on a maturity model in combination with agile methods for the integration and evaluation of implementation has been developed by Schuldt et al. (2020).

An important aspect of the current application is the education of future employees and training of skilled personnel. Given the actuality of the topic, the paucity of teaching approaches - evidenced in an international literature survey conducted by Gust and Sersch (2020) - is striking. Here universities, GPS experts, and standardization bodies should cooperate in developing future-oriented teaching. The facilitation of GPS implementation by improving the structure of the system, refining standards, and providing a guideline for the application of subsets is addressed in ISO/TC 213/WG 17 (working group on "Facilitation of GPS implementation") (International Organization for Standardization (ISO), 2020).

\subsection{Incorrect, ambiguous and/or incomplete specifications}

The aforementioned challenges in the application of GPS can lead to incorrect, ambiguous, and/or incomplete specifications in technical product documentation. In the review of technical drawings from industry this is repeatedly apparent, with common examples found in the following thematic areas:

- $\quad$ non-rigid parts (ISO 10579:2010)

- dimensions other than linear or angular sizes (ISO 14405-2:2018) vs. geometrical tolerancing (ISO 1101:2017)

\subsubsection{Examples}

Figure 3 shows a spider element in an isometric and a selected partial view of a technical drawing. Title blocks and other information that is not necessary for understanding have been omitted. The demonstration part, made of thermoplastic polyurethane (TPU), is used for compensation in a jaw coupling with vibration damping properties. It is intended to illustrate a problem frequently observed in industrial technical drawings. In fact, the elastomeric element in a) is tolerated without reference to ISO 10549, although TPU is considered an elastic material. Because the part is not designated as non-rigid, the tolerances do not describe its functional limits. At the same time, the tolerance requirements in the specification are unnecessarily high. The right side of the figure labeled b) shows the dimensional tolerancing of a distance between two non-planar features. According to ISO 14405, the fundamental occurrence of form deviations in components results in a specification ambiguity as soon as a \pm tolerance for dimensions other than linear or angular sizes is used. This can (and should) be avoided by geometrical specifications.
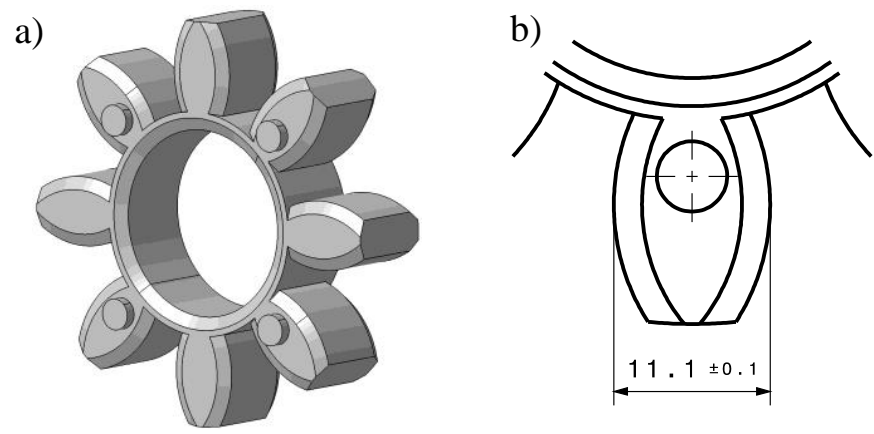

Figure 3. a) Tolerancing of a non-rigid part as rigid b) Dimensional tolerancing of a distance 


\subsubsection{Consequences}

Deficiencies in technical drawings do not necessarily mean that companies are confronted with problems (Läpple, 2019). These can often be compensated by established supplier relationships and existing knowledge of the function of a product. However, problems become visible when a supplier is changed, outsourcing is increased, or the product portfolio and manufacturing process is altered. In such cases, inadequate technical drawings can lead to downstream consequences. Particularly in small and mediumsized enterprises (SMEs), individual change management, often based partly on agreement, can lead to coordination difficulties, making it harder to pinpoint responsibilities and increasing the communication effort.

A non-function-oriented approach to tolerancing and the application of "fear tolerances" will lead to increased production and verification costs. In addition, faults only recorded at a later point in the value chain - or, in the worst case, only noticed by the customer at a later point in time - may well cause complaint costs, and parts may have to be reworked or newly manufactured at considerable expense. An enterprise's reputation can suffer, and if functionally relevant specifications cannot be found in the technical drawing, the manufacturer is more vulnerable to product liability issues. All these consequences ultimately lead to increased costs and competitive disadvantages.

\section{APPROACH BASED ON SCRAP RATE USING TOLERANCE ANALYSIS}

In order to determine the effects of deficient specifications in technical drawings, an approach is presented below that is based on the scrap rate using a tolerance analysis. An introduction to the assembly used to demonstrate the approach is given at the beginning of this section. The detailed procedure is then explained, and the results achieved are presented.

\subsection{Case study}

Figure 4 shows a mechanical roller whose assembly consists of five basic components. Two cylindrical plain bearings with flange (iglidur® ${ }^{\circledR}$ GFM-1517-12) are used for almost frictionless rotation. Axial displacement is prevented by the clamped retaining ring on the shaft shoulder of the axle bolt. The axle bolt is in turn mounted in the bearing block, which serves as the basis of the entire assembly.

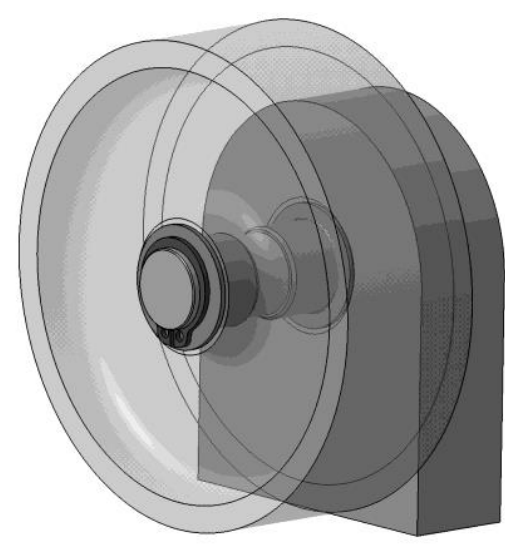

Figure 4. Roller assembly

Deviations occurring in individual components are limited in size and type by tolerances in the technical drawings. But they will influence the movement of the roller within the overall system. Collisions of components with each other caused, for example by inclination of the roller to the bearing block or by deviation in diameters, can lead to jamming of the assembly. 


\subsection{Approach}

Tolerance analysis investigates the impact of deviations derived from technical drawings on the fulfillment of previously defined requirements. The analysis in this paper uses the commercial software VisVSA from Siemens to compare the impact of such deviations in the event of non- or partial application vs. full application of the GPS system.

The tolerance analysis sequence implemented here follows the usual practical order. After importing the nominal geometry and defining the assembly structure, the functional features necessary for assembly, tolerancing, and measurement are generated. These are derived from the individually defined specifications for the features in the technical drawings. The next step is definition of a reference system, and of the tolerances and assembly. To draw conclusions about certain quality features of the assembly, these must be identified before the tolerance analysis is performed and the results analyzed and interpreted. The procedure is shown in Figure 5.

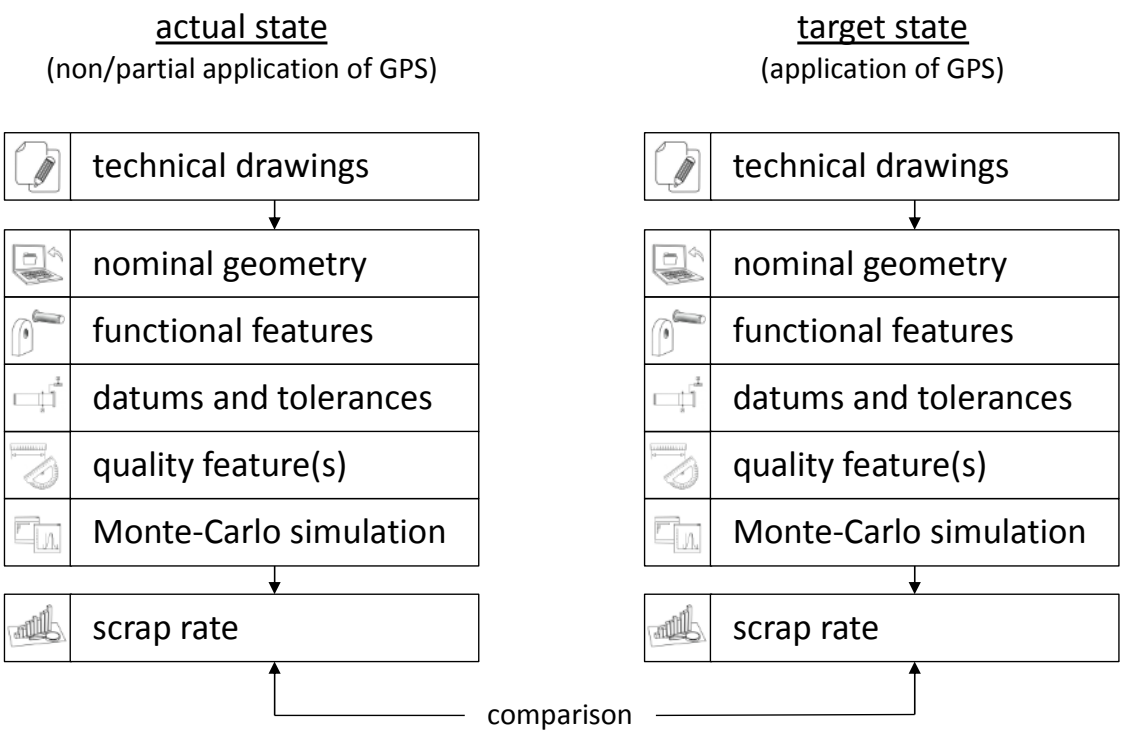

Figure 5. Procedure of the approach

In contrast to the usual procedure, the approach consists in quantitatively capturing the differences in the level of GPS application (ISO standard) in the form of scrap rates. The rates are compared as results of the actual vs. the target state. In this context, the scrap rate is defined as the percentage of samples outside the predefined range between low limit and high limit, the limits being set in accordance with the functional requirements of the roller assembly. The model focuses on the quality feature of the distance between bearing block and roller, which is influenced e.g. by the opposite surfaces on the bearing block and roller as well as the positioning of the holes and the axle bolt.

Input data into the model are the specifications of the technical drawings. In addition to the type of geometrical tolerances, these include datums, dimensional and general tolerances as well as tolerance values. Specifications likely associated with a more advanced application - e.g. specification modifiers for linear sizes - and/or which cannot be reproduced in VisVSA (intersection plane modifiers) are not considered. Figure 6 provides a comparative view of the drawings for the bearing block component, showing a) the actual state and b) a possible target state of the drawing for the selected component. At this point it should be mentioned that the modified drawing represents only one possible way of tolerancing by the author. The comparison of the drawings is intended to increase understanding. For reasons of clarity, no title block is used here either. In both drawings, general tolerances in accordance with DIN ISO 2768-1/2:1991 are nevertheless taken into account and the envelope principle is applied as fundamental tolerance principle. 
a)

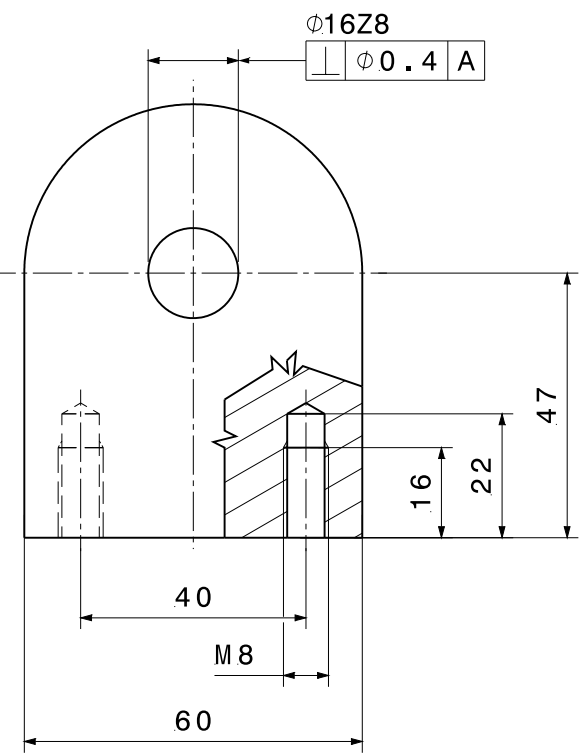

b)

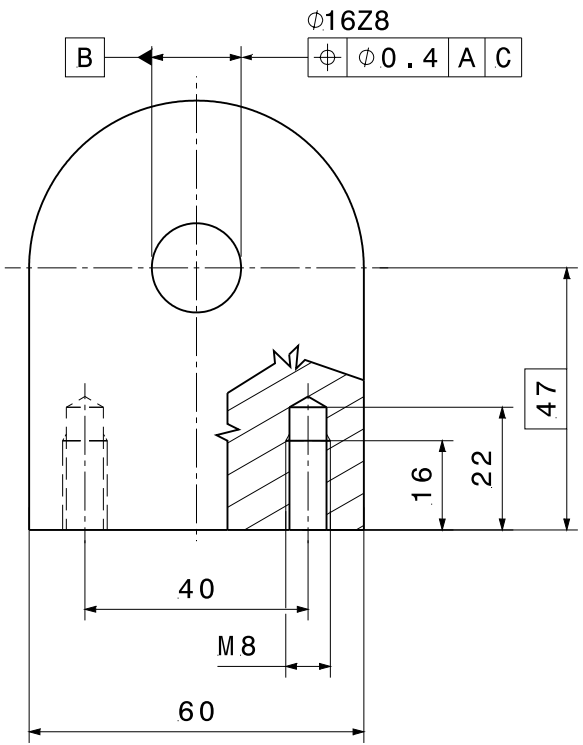

$20.2 \pm 0.05$

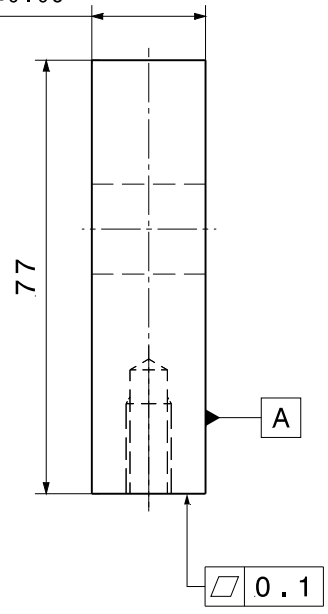

$20.2 \pm 0.05$

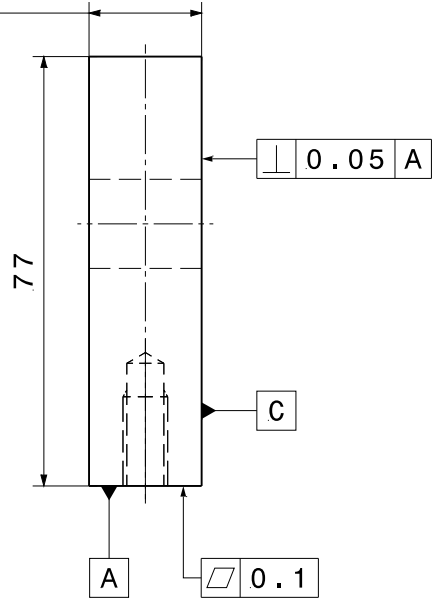

Figure 6. Comparison of the drawings for the bearing block component in a) the actual state and $b$ ) the target state

In the following, the drawing differences of the states to be compared within the procedure described in Figure 5 are explained exemplarily. In the actual state of the drawing the creation of datums is limited to datum A. For a more precise description of the component, however, a supplement to the individual datum is appropriate (ISO 5459:2011). In b), a datum system is used. Also, the location of the hole, which is previously specified by a \pm tolerance, is replaced by a geometrical tolerance, namely a position tolerance. The problems inherent in the application of \pm tolerances have already been described in section 2.2.1. Converting the value $47 \mathrm{~mm}$ into a theoretically exact dimension (TED) completes this specification. Furthermore, the form and position of the datums $\mathrm{A}$ and $\mathrm{C}$ are specified more precisely in the second version of the drawing (flatness and perpendicularity). More improvements of the target state are conceivable, such as the application of symmetry conditions or the replacement of general tolerances by a profile surface tolerance valid for the entire drawing when transferred to other cases. The changes between the drawings in a) and b) are not based on quantitative determinations and therefore cannot be considered completely objective. This limitation of the presented approach will be addressed again in the discussion of this paper.

Within the tolerance analyses the assumption of a normal distribution of tolerances, a tolerance sigma range of $\pm 3 \sigma$ (sigma) and a Monte-Carlo simulation number of 10,000 remains constant. Any variance between the two statistical tolerance analyses can only be found in the specifications in the drawings.

With the above assumptions, and tolerance limits of 0.1 and $1.2 \mathrm{~mm}$ for the distance between bearing block and roller, the initial state of the drawing implies a scrap rate of about $28 \%$ of total samples. 
After changes to the drawing focusing in particular on completing the datums and detailing the geometrical specifications for functionally significant features, the scrap rate reduces to $25 \%$.

\section{Discussion}

Comparison of actual and target results shows only a slight decrease in scrap rate when the drawing is modified. Possible reasons for this are presented below. There are weaknesses in the idea of adducing quantitative information as a function of level of GPS application and in relating costs to comparative scrap rates. However, these point the way to useful future research.

If, for example, general tolerances are specified in the actual state, GPS specifications for functionally essential features can be increasingly applied in the target state in order to fulfill the function. In cases where - due to normative gaps in the area of general tolerances in accordance with DIN ISO 27681/2:1991 - there is no basis for comparison, or where ambiguities from the initial drawings cannot be transferred to the model, the effect on the scrap rate will be erroneous. Here, rather than integrating an optimization loop for tolerance values, two states are compared. During this procedure, the target state of the technical drawing is not a quantitative definition based on objective criteria. When applying Geometrical Product Specifications, it may happen that there are several alternative solutions for a function-oriented description of one component, which are difficult to evaluate against each other. With the limitation to dimensional and geometrical tolerances and tolerance values, datums, and general tolerances, a large part of the GPS system is nevertheless covered. Consequently, the term application - as opposed to non-application or partial application of the system - is still too vague.

Tolerance analysis does, however, enable determination of scrap rates and the checking of functional requirements. The earlier scrap is detected, the lower the cost of corrective action. The quality achieved in a company depends on how successfully expectations are met: In this context, the targets are not only purely tolerance-related, but are also subject to other characteristics as defined in DIN EN ISO 9000:2015. In general, these are, for example, characteristics of a time-related nature, i.e. how punctually and reliably parts are provided, or of an environmental nature, to what extent the manufacturing process and the product life cycle are designed to be recycling-friendly. Deviations from the target state are not necessarily recognized by the customer, but they are still of interest to the enterprise. In the case of scrap, a cost linkage is also possible, taking into account the material costs of the individual components. Other steps possible in such a situation, such as reworking or increased communication with those responsible, have not been addressed here. Implementation can be achieved using tolerance-cost optimization to quantitatively consider quality and cost (Hallmann, 2018), including the various internal and external costs incurred by tolerance allocation (Zhang, 1993). A prerequisite for this is a tolerance-cost model, which may be difficult to determine, as costs are often not directly measurable (Feng, 2008; Terán, 1996). An extension to geometrical tolerances is rarely available (Saravanan, 2014).

\section{CONCLUSION}

This paper describes the application of the GPS system for specifications in technical products. The research questions defined at the beginning can be answered to different extents. Based on the analysis of technical drawings from industry, it is possible to show examples of specifications that occur repeatedly, regardless of company characteristics. Even if these examples do not claim to be complete, typical deficiencies can still be identified. With regard to the second research question, it can initially be stated that reproducible scrap rates can be determined by means of a statistical tolerance analysis. Nevertheless, it is apparent that the results are highly dependent on the assumptions of the technical product documentation due to their nature. Building on these findings, it can thus be consulted that the association of scrap rates with costs is also influenced by the assumption in the tolerance analysis. Furthermore, an extended cost type consideration is not possible within this approach. Linking mostly dimensional tolerances to costs in tolerance cost models is also a complex task.

Especially the mapping of ambiguities in drawings, as well as a detailed definition of basic terms like GPS application or target state, still need further research. One objective of future research is to develop a general approach to analyze and work up a link between the GPS standards system and costs in companies in the first place. Furthermore, the identification and evaluation of production processes based on company key figures has additional potential if the GPS system is taken into account. 


\section{REFERENCES}

Armillotta, A., Semeraro, Q. (2011), “Geometric Tolerance Specification”, In: Colosimo, B., Senin, N. (Eds.), Geometric Tolerances - Impact on Product Design, Quality Inspection and Statistical Process Monitoring, Springer, London, pp. 3-37. https://doi.org/10.1007/978-1-84996-311-4.

DIN ISO 2768-1:1991. Allgemeintoleranzen - Toleranzen für Längen- und Winkelmaße ohne einzelne Toleranzeintragung, Deutsches Institut für Normung e.V. (DIN), Berlin.

DIN ISO 2768-2:1991. Allgemeintoleranzen - Toleranzen für Form und Lage ohne einzelne Toleranzeintragung, Deutsches Institut für Normung e.V. (DIN), Berlin.

Feng Q., Kapur K. (2008), “Quality engineering: control, design and optimization”, In: Misra K. (Ed.), Handbook of Performability Engineering, Springer, London, pp. 171-186. https://doi.org/10.1007/978-184800-131-2 13.

Gust, P. and Sersch, A. (2020), “Geometrical Product Specifications (GPS): A Review of Teaching Approaches”, Procedia CIRP, Vol. 92, pp. 123-128. https://doi.org/10.1016/j.procir.2020.05.187.

Hallmann M., Schleich B., Heling B., Aschenbrenner A., Wartzack S. (2018), "Comparison of different methods for scrap rate estimation in sampling-based tolerance-cost-optimization”, Procedia CIRP, Vol. 75, pp. 5156. https://doi.org/10.1016/j.procir.2018.01.005.

Haq A.N., Sivakumar K., Saravanan R., Muthiah V. (2005), “Tolerance design optimization of machine elements using genetic algorithm”, Int J of Adv Manuf Technol, Vol. 25, No. 3-4, pp. 385-391. https://doi.org/10.1007/s00170-003-1855-z.

International Organization for Standardization (ISO) (2020), ISO/TC: Dimensional and geometrical product specifications and verification. [online] Available at: https://www.iso.org/committee/54924.html (10.09.2020)

ISO/TC 213 (2008), Business Plan - Dimensional and geometrical product specifications and verification. [online] International Organization for Standardization. Available at:

https://isotc.iso.org/livelink/livelink/fetch/2000/2122/687806/ISO_TC_213_Dimensional_and_geometrica 1_product_specifications_and_verification_.pdf?nodeid=999295\&vernum=-2 (accessed 03.01.2018).

ISO 1101:2017-02. Geometrical product specifications (GPS): Geometrical tolerancing - Tolerances of form, orientation, location and run-out, International Organization for Standardization (ISO), Switzerland.

ISO 5459:2011-08. Geometrical product specifications (GPS): Geometrical tolerancing - Datums and datum systems, International Organization for Standardization (ISO), Switzerland.

ISO 8015:2011-06. Geometrical product specifications (GPS) - Fundamentals - Concepts, principles and rules, International Organization for Standardization (ISO), Switzerland.

ISO 9001:2015-09. Quality management systems - Fundamentals and vocabulary, International Organization for Standardization (ISO), Switzerland.

ISO 10579:2010-03. Geometrical product specifications (GPS) - Dimensioning and tolerancing - Non-rigid parts, International Organization for Standardization (ISO), Switzerland.

ISO 14405-2:2018-12. Geometrical product specifications (GPS) - Dimensional tolerancing - Part 2: Dimensions other than linear or angular sizes, International Organization for Standardization (ISO), Switzerland.

ISO 14638:2015-01. Geometrical product specifications (GPS) - Matrix model, International Organization for Standardization (ISO), Switzerland.

Läpple, V. (2019), ISO GPS - Warum Sie Geometrische Produktspezifikationen richtig anwenden sollten. [online] Vogel Communications Group. Available at: https://www.konstruktionspraxis.vogel.de/warum-siegeometrische-produktspezifikationen-richtig-anwenden-sollten-a-819171/ (18.11.2020).

Macleod, I. (2020), Geometrical Product Specification - the work of ISO/TC213, 16th CIRP Conference on Computer Aided Tolerancing (CIRP CAT), Charlotte.

Morse, E.P., Shakarji, C.M., Srinivasan, V. (2018), “A Brief Analysis of Recent ISO Tolerancing Standards and Their Potential Impact on Digitization of Manufacturing”, Procedia CIRP, Vol. 75, pp. 11-18. https://doi.org/10.1016/j.procir.2018.04.080.

Saravanan A., Balamurugan C., Sivakumar K., Ramabalan S. (2014), "Optimal geometric tolerance design framework for rigid parts with assembly function requirements using evolutionary algorithms", Int J Adv Manuf Technol, Vol. 73, No. 9-12, pp. 1219-1236. https://doi.org/10.1007/s00170-014-5908-2.

Schuldt, J., Hofmann, R., Gröger, S. (2020), "Introduction of a maturity model for the assessment of the integration of the GPS system in companies", Procedia CIRP, Vol. 92, pp. 129-133. https://doi.org/10.1016/j.procir.2020.05.188.

Sersch, A. and Gust, P. (2018), "Empirische Untersuchung zur Überprüfung des Anwendungsgrades der Geometrischen Produktspezifikation (GPS)", 8. Workshop Arbeitsgemeinschaft Toleranzmanagement (ATOL), Krefeld, March 2018, https://doi.org/10.13140/RG.2.2.34009.57440.

Sigmetrix (2020), GD\&T Advisor Software. [online] Available at: https://www.sigmetrix.com/products/gdtsoftware/ (25.11.2020) 
Terán A., Pratt D.B., Case K.E. (1996), "Present worth of external quality losses for symmetric nominal-is-better quality characteristics”, Eng Econ, Vol. 42, No. 1, pp. 39-52. https://doi.org/10.1080/00137919608903168.

Zhang C., Wang H. (1993), "Integrated tolerance optimisation with simulated annealing", Int J Adv Manuf Technol, Vol. 8, No. 3, pp. 167-174. https://doi.org/10.1007/BF01749907.

Vornholz, G. (2015), International Immobilienökonomie: Globalisierung der Immobilienmärkte, De Gruyter Oldenbourg, Berlin. https://doi.org/10.1515/9783110437829. 